\title{
SUOMALAISEN LAMPAAN VILLASTA JA SEN TUOTANTOON VAIKUTTAVISTA ULKONAISISTA TEKIJÖISTÄ.
}

\author{
Viljo Vainikainen ja Rauha Hakola \\ Maatalouskoelaitoksen kotieläinjalostusosasto ja \\ Pienviljelijäin Keskusliitto.
}

Saapunut 1. 7. 1952 .

Suomalaisen lampaan villan ominaisuuksia koskevassa aikaisemmassa tutkimuksessa (1) on sen käytännöllisenä lopputuloksena todettu, ettei meillä ole syytä eikä varaakaan luopua erinomaisesti sikiävästä ja oloissamme hyvin viihtyvästä maatiaislampaastamme. Tähän käsitykseen johtivat tutkimuksen tulokset, joiden mukaan maatiaislampaamme villa yleensä on sangen tervettä, jotapaitsi laajan perinnöllisen vạihtelun huomioonottaen meillä on mahdollisuus kehittää lampaita, joiden villapeite eri ruumiinosissa on tasalaatuinen ja jopa eräillä yksilöıllä samaa hienousluokkaakin kuin merinovilla. Tämän lisäksi on esim. Englannissa suomalaisella lampaan villalla suoritetuilla tutkimuksilla todettu se erittäin soveliaaksi tekstiiliteollisuuden raaka-aineeksi hyvän kestävyytensä ja venyvyytensä vuoksi. Lukuisat kudonnaiset, joissa monasti ilmenee suomalaisen villan kaunis kiilto, osoittavat sen soveliaisuutta ja käyttöä käsi- ja kotiteollisuudessa. Usko maatiaislampaamme villan kelpoisuudesta ja hyvyydestä saattaa kuitenkin helposti horjua, jos joudumme sitä arvostelemaan villamme kauppakunnon perusteella. Lampaan kasvattajan myytäväksi tarjoama villa ensinnäkin on, joitakin harvoja poikkeuksia lukuunottamatta, lajittelematonta, siis eri hienousluokkaa olevat villat ovat sekaisin. Sikäli kuin villasta halutaan saada korkein markkinahinta, ja lammastamme ei vielä ole saatu jalostetuksi kautta ruumiin samanlaista villaa tuottavaksi, on kauppaan tuleva villa aina lajiteltava samaan tapaan kuin villa maailman markkinoilla kaupataan. Toinen suomalaisen lampaan kauppavillan heikkous on sen likaisuus. Huolimattomasti tai ahtaiden suojien aiheuttamasta epämukavasta rehujen käsittelystä johtuen, yhden esimerkin mainitaksemme, saattaa villa sisältää monenlaista korsirehusta irtautunutta roskaa, tai se on kuivikkeiden niukasta käytöstä johtuen lannan ja virtsan polttamaa. Nämä ovat sellaisia epäedullisten ulkonaisten tekijöiden aiheuttamia haittoja, jotka jo vähäisellä huolellisuudella voitaisiin helposti poistaa ja siten huomattavalla tavalla parantaa lampaamme villan kauppa-arvoa. Edellämainittujen lisäksi on suomalainen villa useasti niin lyhyttä, että teollisuuden on vaikea sitä hyödyllisesti käyttää. Sanottu lampaamme villan lyhytkuituisuus 
johtuu useassa tapauksessa liian monesta keritsemiskerrasta. Kun kuitenkin on ollut syytä olettaa, että keritsemiskertojen ohella saattaa olla toisiakin villan lyhyyteen vaikuttavia syitä, päätettiin asia ottaa selvitettäväksi samalla toivoen, että sanotun tarkastelun yhteydessä ilmenisi muitakin suomalaisen lampaan villan tuotantoa hyödyttäviä seikkoja.

Tutkimusaineisto, jonka keruusta on huolehtinut Hakola, on koottu Pienviljelijäin Keskusliiton lammastarkkailuun ja lammastalouskilpailuun osallistuneilta tiloilta pääasiassa Pohjois-Savosta ja Etelä-Pohjanmaalta. Aineisto, jonka muodostaa 97 uuhta, käsittää tulokset kolmelta peräkkäiseltä keritsemiskerralta, joten jokaiselta aineistoon kuuluvalta lampaalta on saatu talvi-, kevät- ja kesäkauden villan tuotannot. Tutkimuksessa talvivillaksi nimitetty villa on kasvanut ajan 1. 10—31. 1, kevätvilla 1. $2-31.5$ ja kesävilla 1. 6. -30. 9 välisenä aikana kuitenkin siten, että aikamäärittelyssä on 10 päivän ylitys ollut sallittu villan joutumatta seuraavaan aikaryhmään. Mainittuina ajankohtina on jokaiselta lampaalta otettu villanäyte lavalta, kyljeltä, selästä ja reideltä. Aineistoon sisältyy lisäksi uuhien syyspainot, jokaisen uuhen karitsamäärä sekä karitsain yhteispaino 6 kk:n ikäisenä. Aineistoon liittyy lisäksi yleisluontoiset selostukset tilojen lampoloista, lampaiden talvi- ja kesäruokinnasta sekä laitumien kasvukunnosta.

Aineisto on tutkittu Maatalouskoelaitoksen kotieläinjalostusosastolla VAINIKAISEN johdolla, joka samalla on varustanut tutkimuksen tekstillä. Villakarvojen hienous on mitattu samaa tapaa käyttäen kuin aikaisemmassa tutkimuksessa (1), jossa keskihienous laskettiin 75 villakarvan mittauksen perusteella. Villan pituus on mitattu pöydälle pingoitetusta näytteestä. Kun näytteet ovat muodostuneet melko tasalatvaisista tapuleista, on mittaus ollut helppo suorittaa riittävällä tarkkuudella. Tulokset on laskettu aikaisemmassa tutkimuksessa (1) esitettyjä matemaattisia kaavoja käyttäen.

Kuten taulusta ilmenee, on talvivilla ollut hienointa ja kesävilla karkeinta. Samaten on lapavilla ollut läpimitaltaan ohuinta sekä sitä lähinnä kylki- ja selkävilla, reisivillan ollessa karkeinta. Molemmissa tapauksissa ovat keskiarvojen erotukset kuitenkin siksi vähäiset, ettei niillä ole käytännöllistä merkitystä. Tutkitussa aineistossa on ollut useita sellaisia lampaita, joiden villan hienousaste eri ruumiinosissa on ollut sama.

Taulu 1. Lapa-, kylki-, selkä- ja reisivillan keskimääräiset hienoudet.

Tabelle 1. Die durschnittlichen Feinheiten von Bug-, Flanken-, Rücken-und Schenkelwolle.

\begin{tabular}{lcccc}
\hline & Lapa & Kylki & Selkä & Reisi \\
& Bug & Flanke & Rücken & Schenkel \\
\hline $\begin{array}{l}\text { Talvivilla } \\
\text { Winterwolle }\end{array}$ & $22.52 \pm 0.26$ & $23.11 \pm 0.28$ & $23.36 \pm 0.27$ & $25.73 \pm 0.33$ \\
$\begin{array}{l}\text { Kevätvilla } \\
\text { Frühjahrswolle }\end{array}$ & $23.82 \pm 0.32$ & $23.84 \pm 0.40$ & $24.84 \pm 0.35$ & $26.86 \pm 0.41$ \\
$\begin{array}{l}\text { Kesävilla } \\
\text { Sommerwolle }\end{array}$ & $24.40 \pm 0.24$ & $24.82 \pm 0.26$ & $25.51 \pm 0.25$ & $26.86 \mp 0.30$ \\
\hline
\end{tabular}


Kun tutkimuksessa eri keritsemiskerroilta kerätty aineisto on peräisin samoista lampaista, on ollut kiintoisaa todeta, onko villan keskihienouksien välillä vuorosuhdetta. Tulokset, jotka on laskettu vain lavalta otetun näytteen perusteella osoittavat, että talvi- ja kesävillan keskihienouden välillä on vallinnut vuorosuhde $\mathrm{r}=$ $+0.284 \pm 0.098$ sekä kevät- ja kesävillan välillä vastaavasti $r=+0.276 \pm 0.102$. Mainitut vuorosuhteet ovat lukuarvoltaan vähäiset, mutta ennen kaikkea ovat ne merkityksettömät suuren keskivirheensä vuoksi, joka tekee ne matemaattisesti epäluotettaviksi. Tämän mukaan ei siis suomalaisen lampaan talvi- eikä kevätvillan keskihienouden perusteella voida saada edes osapuilleen luotettavaa käsitystä saman lampaan kesävillan keskihienoudesta. Kun kysymys on saman lampaan eri kasvukausina tuotetusta villasta, on tulos jossain määrin odottamaton, vuorosuhde toisin sanoen kovin vähäinen. Tulos on ilmeisesti ymmärrettävissä vain siten, että määrätyt ulkonaiset olosuhteet, lähinnä ruokinta ja hoito vaihtelevat villan eri tuotantokausina. Kuten myöhemmin lähemmin selviää, onkin monilla aineistoon kuuluvilla tiloilla lampaiden talvi- ja kevätkauden ruokinta ollut niukkaa, samanaikaisesti kun talvisuojat ovat olleet ahtaat ja kosteat. Toisaalta on aineistoon kuulunut sellaisiakin tiloja, joilla lampaiden elinehdot kesällä, ensi kädessä huonokasvuisten laitumien vuoksi ovat olleet epäedullisemmat kuin sisäruokintakaudella. Kun tällaiset ulkonaiset tekijät saattavat muuttaa villan keskihienouden toiseksi kuin perinnöllinen laatu edellyttää, on ymmärrettävissä, että tämä vaikutus ilmenee ylläesitetyssä vuorosuhdekertoimien suuruudessa ja luotettavuudessa. Tämän käsityksen varmistamiseksi suoritetaan myöhemmin uusi tutkimus, johon aineisto kerätään ruokinnan riittoisuuden ja monipuolisuuden sekä hoidon tarkoituksenmukaisuuden suhteen luotettavista olosuhteista.

Kuten aikaisemmin jo on mainittu, ovat tutkimuksessa huomioidut villan kasvukaudet olleet neljän kuukauden pituiset siihen kuitenkin lisättynä 1o päivän mahdollinen ylitys. Alkuperäisen aineiston mukaan laskettuna on villan todellinen kasvuaika talvikautena ollut keskimäärin $128.62 \pm 2.42$ päivää, kevätkautena 115.32 \pm 2.25 sekä kesäkautena $121.21 \pm 2.06$ päivää. Aineistoon kuuluneiden lampaiden keskimääräinen villasato on ollut $2.44 \pm 0.06 \mathrm{~kg}$ vuodessa, yksityisten lampaiden vuosituotantojen vaihdellessa 1.4 ja $3.7 \mathrm{~kg}$ välillä.

Eri kasvukauden villamääriä toisiinsa verrattaessa ilmenee, että villan kasvu on ollut runsain kesäkautena muodostaen sen osuus $47.7 \pm 0.8 \%$ vuosituotannosta. Vastaava tuotanto-osuus on talvikautena ollut $31.5 \pm 0.7 \%$ ja kevätkautena 21.8 $\pm 0.8 \%$. Kuten edellä jo ilmeni, ovat tutkimuksessa tarkastetut villan kasvukaudet olleet käytännöllisesti katsoen yhtä pitkät, joten niiden aikana tuotettuja villamääriä voitanee pitää sinänsä vertailukelpoisina. Mahdollisimman tarkan kasvuintensiteetin osoittamiseksi on tutkimuksessa kuitenkin lisäksi laskettu villan kasvu 100 päivää kohti. Tämän mukaan ovat lampaat kesäkautena 100 päivässä tuottaneet keskimäärin $966.8 \pm 24.0 \mathrm{~g}$ villaa sekä talvikautena vastaavasti $601 \pm 21 \mathrm{~g}$ ja kevätkautena $476.6+23 \mathrm{~g}$. Kesäkaudella on siis ratkaiseva osuus villantuotannossamme. Kun tiedot on kerätty samoilta lampailta kaikilta kyseessäolevilta tuotantokausilta, on mielenkiintoista todeta, että useimmissa tapauksissa kesäkauden villlasato on ollut runsas samojen lampaiden vastaavan tuotannon kevätkautena jäädessä aivan 
Taulu 2. Lapa-, kylki-, selkä- ja reisivillan keskimääräiset pituudet sm.

Tabelle 2. Die durschnittlichen Längen von Bug-, Flanken-, Rücken- und Schenkelwolle cm.

\begin{tabular}{lcccc}
\hline & $\begin{array}{c}\text { Lapa } \\
\text { Bug }\end{array}$ & $\begin{array}{c}\text { Kylki } \\
\text { Flanke }\end{array}$ & $\begin{array}{c}\text { Selkä } \\
\text { Rücken }\end{array}$ & $\begin{array}{c}\text { Reisi } \\
\text { Schenkel }\end{array}$ \\
\hline $\begin{array}{l}\text { Talvivilla } \\
\text { Winterwolle }\end{array}$ & $5.40 \pm 0.16$ & $5.2 \pm 00.17$ & $5.42 \pm 0.18$ & $5.72 \pm 0.20$ \\
$\begin{array}{l}\text { Kevätvilla } \\
\text { Frühjahrswolle }\end{array}$ & $4.93 \pm 0.20$ & $4.97 \pm 0.20$ & $5.16 \pm 0.20$ & $5.45 \pm 0.20$ \\
$\begin{array}{l}\text { Kesävilla } \\
\text { Sommerwolle }\end{array}$ & $6.90 \pm 0.21$ & $7.21 \pm 0.24$ & $7.05 \pm 0.23$ & $7.73 \pm 0.26$ \\
\hline
\end{tabular}

merkityksettömäksi. Tällaisia tapauksia lähemmin tutkittaessa selviää, että lampaiden ruokinta on talvi- mutta erikoisesti kevätkaudella ollut riittämätön ja yksipuolinen, samalla kun lampaat saavat talvehtia ahtaissa, kuumissa ja ammoniakkihöyryjen kyllästämissä suojissa. Kun lampaamme kykenevät kesän aikana tuottamaan suunnilleen puolet koko vuoden villamäärästä, on ilmeistä, ettei lampaittemme perinnöllinen laatu ole esteenä nykyistä korkeampien vuosituotantojen saavuttamiselle. Edellämainittuja tuotantonumeroita tarkastaessa ei voi välttyä ajatukselta, että saattamalla lampaiden ruokinta sekä hoito talvi- ja kevätkaudella edes kesäkauden olosuhteita vastaaviksi olisi meillä sanotuilla toimenpiteillä helppo korottaa keskimääräinen villantuotanto lammasta kohden ainakin 3 $\mathrm{kg}$ :ksi vuodessa.

Tutkimuksessa tarkastettujen lampaiden villan pituudet eri ruumiinosissa ilmenevät oheellisesta taulusta 2 .

Taulukon mukaan on kevätvilla kaikissa tutkimuksessa tarkastetuissa näytteissä jäänyt lyhimmäksi, kesävillan vastaavasti saavuttaessa suurimman pituuden. Tämä on jälleen ilmeinen seuraus ulkonaisten olosuhteiden vaikutuksesta, jota tässä tapauksessa ei ole pidettävä käytännöllisesti merkityksettömänä, koska keskipituuksien erot ovat eräässä tapauksessa ylittäneet 2:kin sm. Eri ruumiinosista samana kasvukautena otettujen villanäytteiden keskipituudet eivät sitävastoin ole suurestikaan poikenneet toisistaan.

Villan hienouden ja pituuden välistä vuorosuhdetta laskettaessa on rajoituttu ainoastaan lampaan lavalta otettuihin näytteisiin. Ottamalla huomioon jokaiselta lampaalta talvi-, kevät- ja kesäkauden villasadon, on aineisto käsittänyt 279 lammasta. Edellämainittujen ominaisuuksien väliseksi vuorosuhteeksi on tällöin saatu $\mathrm{r}=+0.24 \pm 0.06$. Käyttämällä ainoastaan kesäkauden aineistoa, jolloin yksilömäärä on ollut 98 lammasta, on villan hienouden ja pituuden väliseksi vuorosuhteeksi saatu $r=+0.28 \pm 0.09$. Molemmat mainitut vuorosuhdekertoimet ovat samaa suuruusluokkaa ja matemaattisesti varmat. Vaikka ne lukuarvoltaan ovatkin melko pienet, on niissä ainakin viitettä siihen suuntaan, että karkea villa on jonkin verran pitempää kuin hieno villa.

Edellä on toisessa yhteydessä jo todettu, että epäedulliset ulkonaiset tekijät vaikuttavat haitallisesti talvi- ja kevätvillan tuotantomäärään Tästä syystä on seu- 
raavassa villan hienouden ja määrän välistä vuorosuhdetta laskettaessa käytetty yksinomaan kesäkauden aineistoa, ja on r:n arvoksi saatu $+0.45 \pm 0.08$. Mainitusta kertoimesta, joka on lukuarvoltaan merkittävän korkea, samalla kun se on matemaattisesti varma, ilmenee selvästi, että villan muuttuessa karkeammaksi, villamäärä lisääntyy. Tämän seikan ovat lampaiden kasvattajatkin todenneet ja siitä syystä he virallisesta jalostusohjelmasta ja sopivasta jalostusaineistostakin huolimatta kasvattavat karkeavillaisia lampaita mieluummin kuin hienovillaisia. Edellä sanotun perusteella on ilmeistä, että sikäli kuin lampaan kasvattajien makusuuntaa halutaan kehittää hienovillaista lammasta suosivaksi, on se saavutettavissa ainoastaan siten, että hienosta, vähintään 60 engl. hienousastetta olevasta villasta maksetaan tuntuvasti, vähintäin 2 kertaa korkeampi hinta kuin karkeasta villasta.

Yksityisten lampaiden talvı- ja kevätkauden pieniä villasatoja kesäkauden villantuotantoon verrattaessa voidaan yhtenä tärkeänä tuotantojen määrien vaihteluun vaikuttavana tekijänä todeta ruokinnan yksipuolisuus ja niukkuus. Tiloilta saatujen tietojen mukaan saavat lampaat talvi- ja kevätkaudella pääasiassa ravintoarvoltaan heikkoja heiniä ja olkia. Läheskään kaikilla tiloilla ei ole ollut lehdeksiä, ja niilläkin tiloilla, joilla tätä rehua on ollut, ei sitä ole riittänyt koko sisäruokintakaudeksi. Eräiltä tiloilta saapuneissa selostuksissa mainitaan lampaiden talvi- ja kevätkauden rehuannoksiin kuuluvan myös kuorittua maitoa, kaurajauhoja, keittiöjätteitä, A.I.V.-rehua, perunaa, kivennäisaineita j.n.e., joilla rehuilla ruokintaa on täydennetty pääasiassa tunnuttamis- ja imettämisvaiheessa. Kun näissäkin olosuhteissa kuitenkin kesäkauden villamäärä on ollut runsain, ovat rehuannokset joko olleet liian niukat, mitä ei voida tämän yhteydessä yksityiskohtaisemmin tarkastaa, tai sitten kyseessäolevilla tiloilla on ollut muita epäedullisia ulkonaisia tekijöitä kuin ruokinta.

Tilannetta edelleen tarkastettaessa voidaankin todeta, että ruokinnan ohella toinen lammastaloudessamme tavattava epäedullinen ulkonainen tekijä on ymfäristë, jossa lampaat joutuvat sisäruokintakautensa viettämään. Aineistoon kuuluneista lampaista on, tiloilta saatujen selostusten mukaan suurin osa, n. $73 \%$, ollut talvella navetassa ja vain harvassa tapauksessa, n. $20 \%$, on tilalla ollut lampola, viimeksimainitunkin vain muutamalla tilalla täyttäessä aianmukaiselle lampola!le asetettavat vaatimukset. Navetta on yleensä lampaiden pitempiaikaista oleskelua varten sopimaton. Ilma siellä on epäpuhdasta, kosteata ja ammoniakkipitoista ja ennen kaikkea lampaille liian lämmin. Jatkuva kostea ilma aiheuttaa lampaan hikoilemisen, ruokahalu häviää ja lopulta villa rnpeaa lähtemään siten villasatoa alentaen. Samat haitat ilmenevät lampoloissakin, ellei niitä joka päivä runsaasti tuuleteta. Lampaiden pitäminen ahtaissa, kosteissa navetan nurkissa johtunee osittain välinpitämättömyydestä, osittain siitä harhakäsityksestä, että lammas muka vaatii erikoisesti karitsoimisaikanaan lämmintä suojaa. Tämä on kuitenkin harhakäsitys. Lampaan- ja Vuohenhoitoyhdistyksen jo useamman vuoden aikana järjestämistä kokeista nimittäin on ilmennyt, että lampaat voidaan huoleti pitää kautta vuoden ulkona. Ainoa ylellisys, mikä lampaille mainituissa kokeissa suotiin, oli harvaseinäinen vaja, jonne lampaat öisin sekä pahimman sateen ja pyryn aikana suojautuivat. Tämän yhteydessä lienee syytä korostaa, ettei uuhia edes karitsoimisvaiheessa 
siirretty lämpöisiin suojiin. Näiden kokeiden mukaan ei lampaiden kasvatuksen esteenä ainakaan vastaisuudessa pitäisi olla, kuten monasti aikaisemmin on väitetty, kalliiden lampoloiden rakentaminen. Päinvastoin raittiissa ulkoilmassa lampaat tuottavat parhaan villasatonsa edellyttäen luonnollisesti, ettei ruokinnan niukkuus muodostu villan kasvua estäväksi tekijäksi. Ennen kaikkea lampaat tällöin välttyvät nıiltä kärsimyksiltä, joita ne pitkän talvikauden aikana joutuvat kuumissa ja ummehtuneissa navetoissa kokemaan.

Kesäkauden ruokintaolosuhteita on tutkimuksen aineistoon kuuluvien lampaiden osalta vaikea selvittää, sillä eri tiloja koskevassa selostuksessa lyhyesti vain mainitaan, onko kysymyksessä metsä-, haka- tai peltolaidun sekä mahdollisesti jotain laitumen kasvukumnosta. Vertailuja sisäruokintakauden olosuhteisiin voidaan tehdä yksinomaan villamäärien perusteella, jotka edellä suoritetun tarkastelun mukaan ovat olleet kesäkautena runsaimmat ja siten viittaavat edullisempiin ulkonaisiin olosuhteisiin. Eräitä poikkeuksia kuitenkin löytyy. Niinpä aineiston 85 lampaasta on 6 lammasta tuottanut talvivillaa yhtä paljon ja 3 lammasta runsaammin kuin kesävillaa. Ulkonaisia olosuhteita tarkastettaessa on selvinnyt, että mainıttujen 6 lampaan sekä talvi- että kesäruokinta ovat olleet hyvät, kun sitävastoin 3 viimeksimainitun lampaan kesäruokinta on heikkojen laitumien vuoksi ollut puutteellista, mutta talviruokinta sitävastoin runsas ja monipuolinen.

Kuten edellä jo on useampaan otteeseen todettu, on tutkimuksessa tarkastettujen lampaiden heikko villasato johtunut epäedullisista ulkonaisista olosuhteista. Kun suomalainen uuhi tavallisesti synnyttää vähintään kaksoset, mutta useasti useammankin karitsan, on selvää, että niissä olosuhteissa, joissa uuhi itse kuumassa ja ahtaassa suojassa eläen näkee nälkää, usean karitsan synnyttäminen ja imettäminen luonnollisesti vaikeuttaa tilannetta. Tällaisissa olosuhteissa voidaan siis karitsojakin pitää uuhen villantuotantoa vähentävänä tekijänä. Niinpä esimerkkinä voidaan mainita, että oheellisen tutkimuksen aineistossa on ollut kaksi uuhta, jotka ovat antaneet vähimmin, nim. 1.40 ja $1.50 \mathrm{~kg}$ villaa vuodessa. Mainitut uuhet, jotka ovat olleet sekä talvella että kesällä niukalla ravinnolla ja lisäksi talvella kosteassa navetan karsinassa, ovat lisäksi kumpikin antaneet 3 karitsaa. Kun mainitut karitsat 6 kuukauden vanhoina ovat painaneet keskimäärin $25 \mathrm{~kg}$, on suoranainen ihme, että k.o. emiltä on riittänyt ravintoa edes yllämainittuihin villamääriin. Tämän yhteydessä on vielä syytä korostaa, että suuri karitsamäärä voi aiheuttaa emälle villakatoa sen vuoksi, että karitsat emän maatessa kisailevat sen päällä, jolloin villa helposti irtaantuu. Tästä johtuen erään aineistoon kuuluvan 3 karitsan emän keväinen villasato jäi $100 \mathrm{~g}$ :aan. Ilmeistä kuitenkin on, että karitsojen aiheuttama villakato pääasiassa ilmenee epäedullisissa ulkonaisisssa olosuhteissa.

Mielenkiintoista on todeta, että aineiston keskikaritsamäärä on ollut $2.52 \pm$ 0.1 karitsaa. 23 uuhta on synnyttänyt $3-5$ karitsaa ja niistä on otettu eloon vähintään 3 karitsaa. Sanottujen emien keskivillamäärä on ollut $2.40 \mathrm{~kg}$ vuodessa, samalla kun karitsain keskipaino $6 \mathrm{kk}: \mathrm{n}$ vanhana on ollut keskimäärin $30.6 \mathrm{~kg}$. Edelleen on aineistossa ollut 3 uuhta, joiden jokaisen synnyttämät 4 karitsaa on otettu eloon. Mainittujen uuhien vuotuiset villamäärät ja karitsain $6 \mathrm{kk}$ :n kokonaiselopainot ovat olleet seuraavat $2.95-116 \mathrm{~kg}, 2.35 \mathrm{~kg}-119 \mathrm{~kg}$ ja $1.90 \mathrm{~kg} 120-\mathrm{kg}$. Näihin erinomai- 
siin tuotantoihin onkin, kuten tapausten yksityiskohtainen tarkastelu osoittaa, päästy runsaalla ja monipuolisella talvirehulla sekä ravintorikkailla laitumilla.

Mitä sitten villan keritsemiskertoihin tulee, niin huomioon ottamatta, että teollisuus asettaa suomalaisella villalle vähimmäisvaatimukseksi $8 \mathrm{sm}$ :n kuitupituuden, on villa ohellisessa aineistossa keskimäärin ollut sitä lyhyempää, kuten taulukosta 2 ilmenee. Aineistoon kuuluvien yksityisten lampaiden villakuitujen pituuden huomattavasta vaihtelusta kuitenkin selviää, että kolmeakin keritsemiskertaa käyttäen, kuten tutkitussa aineistossa on tehty, voidaan päästä edellä vaatimukseksi asetettuun kuitupituuteen. Tämä kuitenkin edellyttää viileitä ja kuivia suojia sekä lampaiden riittävää ja tarkoituksenmukaista ruokintaa. Näistä ehdottomina pidettävistä vaatimuksista vähintäkään tinkimättä olisi edelläesitettyyn Lampaanja Vuohenhoitoyhdistyksen kokeiluun viitaten, ajateltavissa siirtymistä nykyisestä kolmesta keritsemiskerrasta kahteen keritsemiseen. Lampaat olisivat kautta vuoden pidettävä ulkona vain harvaseinäinen vaja huonojen ilmojen suojana ja ensimmäinen keritseminen olisi suoritettava huhtikuun alussa ja toinen lokakuun lopussa, jolloin kumpikin villan kasvukausi olisi 6 kuukautta. Sikäli kuin tällainen toimenpide pääsisi, kuten toivottavaa olisi, yleistymään, merkitsisi se valtavaa edıstysaskelta suomalaisen lampaan villan laadussa ja määrässä.

KIRJALLISUUTTA.

(1) Terho T. ja Vainikainen, V. 1398. Suomalaisen lampaan villan ominaisuuksista. Referat: Úber die Eigenschaften der finnischen Schafwolle. Valt. maataloustiet. julk., 102.

REFERAT.

ÜBER DIE WOLLE DES FINNISCHEN SCHAFES UND DIE ÄUSSEREN VORBEDINGUNGEN IHRER ERZEUGUNG

Viljo Vainikainen und Rauha Hakola.

Die landwirtschaftliche Versuchsanstalt, Abteilung für Haustierzüchtung, Tikkurila, und Centralverband der Kleinbauer, Helsinki.

Das Untersuchungsmaterial ist in Nord-Savo und Süd-Ostbottnien gesammelt worden in Kleinbetrieben, die am Schafwirtschafts-Wettbewerb des Zentralverbands der Kleinbauern teilgenommen haben. Von jedem der 97 in das Material eingehenden Mutterschafe hat man die Wollproduktionen der Winter-, der Frühjahrs- (die zus. die Stallfütterungszeit bedeuten) und der Sommerzeit (Weidezeit) gewonnen. Die als Winterwolle bezeichnete Wolle ist vom 1. 10.-31. 10 gewachsẹn, die Frühjahrswolle 
vom 1. 2.-31. 5. und die Sommerwolle vom 1. 6.-30. 9. Bei den angeführten Zeitangaben ist jedoch ein 10 tägiges Überschreiten gestattet gewesen, ohne dass die Wolle der folgenden Zeitgruppe zugezählt worden wäre. Die Behandlung des Materials ist dieselbe gewesen wie bei der früheren Untersuchung (1).

Die durchschnittliche Feinheit der Wolle geht aus Tabelle 1 hervor. Danach sind die Bugwolle sowie die ihr zunächst gewachsene Flanken- und Rückenwolle am dünnsten, während die Schenkelwolle am gröbsten ist. Züchterisch ist es wichtig festzustellen, dass das Material jedoch solche Mutterschafe umfasst hat, deren Wolle an den verschiedenen Körperteilen gleicher Feinheitsklasse gewesen ist. Nach Tabelle 1 ist die Winterwolle am feinsten und die Sommerwolle am gröbsten gewesen, aber die Differenzen der Mittelwerte sind indes so gering, dass sie nicht von nennenswerterer praktischer Bedeutung sind.

Zwischen der mittleren Feinheit der Winter- und der der Sommerwolle ist $r=+0.284 \pm 0.098$ gewesen und entsprechend zwischen der Frühjahrs- und der Sommerwolle $r=0.276 \pm 0.102$. Die angeführten Korrelationen sind in Anbetracht des grossen mittleren Fehlers belanglos.

Die wirkliche Wuchszeit der Wolle hat in der Winterzeit durchschnittlich $128.62 \pm 2.42$, im Frühjahr $115.32 \pm 2.25$ sowie in der Sommerzeit 121.21 \pm 2.06 Tage gedauert. Der durchschnittliche Wollerttrag hat im Material jährlich $2.44 \pm 0.06 \mathrm{~kg}$ ausgemacht, während er sich bei den einzelnen Schafen auf $1.4-3.7 \mathrm{~kg}$ belaufen hat. Die Wollerzeugung der Sommerzeit hat im Mittel $47.7 \pm 0.8 \%$ der Jahresproduktion betragen, die der Winterzeit entsprechend $31.5 \pm 0.7 \%$ und die des Frühjahrs $21.8 \pm 0.8 \%$. In der Sommerzeit haben die Schafe, auf 100 Tage berechnet, im Mittel $966.8 \pm 24.0 \mathrm{~g}$ Wolle erzeugt, in der Winterzeit $601.0 \pm 21.0 \mathrm{~g}$ und im Frühjahr $276.6 \pm 23.0 \mathrm{~g}$. Die schwache Wollprofuktion der zwei letztgenannten Zeiträume beruht, wie sich bei eingehender Betrachtung des Materials gezeigt hat, auf knapper Fütterung sowie vor allem darauf, dass die Schafe während der ganzen Stallfütterungszeit, also etwa $8 \mathrm{Mt}$, in engen, dunklen, heissen Kuhställen mit einer von Ammoniakdämpfen gesättigten Luft gehalten werden.

Nach Tabelle 2 ist die Frühjahrswolle bei allen in der Untersuchung geprüften Proben am kürzesten geblieben, während die Sommerwolle entsprechend die beträchtlichste Länge erlangt. Dies ist wieder eine offensichtliche Folge des Einflusses verschiedenartiger äusserer Bedingungen, der in diesem Falle nicht als praktisch belanglos zu gelten hat. Die mittleren Längen der in einer und derselben Wuchsperiode von den verschiedenen Körperteilen erhaltenen Wollproben dagegen sind nicht sehr voneinander unterschieden gewesen.

Als Korrelation zwischen Feinheit und Länge der Wolle hat sich $r=+0.28 \pm 0.09$ ergeben. Obgleich sie von geringem Zahlenwert ist, gibt sie doch einen Hinweis in der Richtung, dass grobe Wolle etwas länger als feine ist. Dasselbe tritt auch bei den Wollmengen hervor, bei denen die auf Grund des Sommermaterials berechnente Korrelation zwischen Wollfeinheit und -menge $0.45 \pm 0.08$ betragen hat.

Neben der dürftigen Fütterung haben die unzweckmässigen Winterunterkünfte nachteilig auf die Wollerzeugung der Schafe eingewirkt. So haben von den Schafen des Untersuchungsmaterials nur $20 \%$ den Winter in einem eigentlichen Schafstall verbracht, während dagegen $73 \%$ mit den Kühen zusammen im Kuhstall gewesen sind. Dessen heisse und feuchte Luft hat denn auch bei gewissen Tieren einen merklichen Haarausfall und -verlust verursacht, ja sogar in dem Masse, dass der Wollertrag der Winterzeit nicht mehr als $100 \mathrm{~g}$ betragen hat. Die den Wollertrag herabsetzende Wirkung dürftiger Fütterung und unzweckmässiger Pflege ist in gewissen Fällen ferner durch die hohe Lämmerzahl gesteigert worden. Die durchschnittliche Menge der von den Muttertieren des Materials erhaltenen Lämmer hat $2.52 \pm 0.1$ ausgemacht. 23 Mutterschafe haben 3-5 Lämmer geboren, und von diesen sind wenigstens 3 aufgezogen worden. Die durchschnittliche Wollmenge der betreffenden Mütter hat $2.4 \mathrm{~kg}$ jährlich und das durchschnittliche Gewicht der Lämmer in einem Alter von 6 Mt $30.6 \mathrm{~kg}$ betragen. Ferner haben 3 Mutterschafe des Materials je 4 Lämmer geboren, die aufgezogen worden sind. Die Wollmengen dieser Mütter sind im Jahre und das Gesamtgewicht ihrer Lämmer im Alter von $6 \mathrm{Mt}$ wie folgt gewesen: $2.95 \mathrm{~kg}$ Wolle $117 \mathrm{~kg}$ Lebendgewicht, $2.35 \mathrm{~kg}-119 \mathrm{~kg}$ und $1.90 \mathrm{~kg}-120 \mathrm{~kg}$. Diese Ergebnisse sind durch reichliche und vielseitige Winterfütterung sowie nährstoffreiche Weiden erlangt worden, so dass der nachteilige Einfluss der Lämmer auf die Wollerzeugung keine primäre Ursache ist, sondern in erster Linie in ungünstigen äusseren Verhältnissen hervortritt.

Bei den untersuchten Schafen ist die Länge der Wolle im Vergleich mit den von der Industrie als Minimalforderung angesetzten $8 \mathrm{~cm}$ durchschnittlich zu kurz gewesen. Dabei sind die Schafe $3 \mathrm{mal}$ 
jährlich geschoren worden, so dass man zur Gewinnung längerer Wollfasern in der Schafwirtschaft Finnlands zu zweimaliger Schur im Jahre überzugehen hätte. Diese Massnahme ist mit Rücksicht auf den Wollertrag aber nur dann möglich, wenn die Schafe in kühlen und trockenen Räumen überwintern können oder das ganze Jahr über im Freien bleiben. Die Möglichkeiten, letzteres durchzuführen, sind schon viele Jahre erprobt worden, indem man die Schafe das ganze Jahr über im Freien gehalten hat, wo ihnen nur eine Bretterhütte mit lichtgezimmerten Wänden bei den schlimmsten Regenfällen und Schneestürmen als Unterschlupf gedient hat. In derartigen Verhältnissen haben die Mutterschafe auch gelammt, eines sogar bei einer Kälte von $28^{\circ} \mathrm{C}$ ohne die geringste Beeinträchtigung. Die in die Versuche einbezogenen Schafe sind gesund und frisch geblieben, ihre Wolle ist rein und von schönem Glanz gewesen, und auch ihr Wollertrag ist durchweg grösser ausgefallen als zuvor, als die Schafe in warmen Unterkünften gewesen waren.

Da die Wollerzeugung des finnischen Schafes nach Ansicht der Verfasser am meisten durch Hitze, Feuchtigkeit und Enge der Kuhställe beschränkt wird, hat man, vielleicht abgesehen vom nördlichsten Finnland, die Schafe das ganze Jahr über im Freien aufzuziehen, wie es in den Versuchen geschehen ist. Durch zweckmässige Fütterung der Schafe lässt sich unter den besagten Verhältnissen die wirkliche Wollerzeugungsneigung herausstellen, und es ist wahrscheinlich, dass statt der jetztigen $2 \mathrm{~kg}$ Erzeugung denn auch schon eine durchschnittliche Erzeugung von 3 Wollkilogram in Frage kommen kann. 